\title{
Efectos de la modificación en el tratamiento de la diferencia en cambio: impacto contable y financiero
}

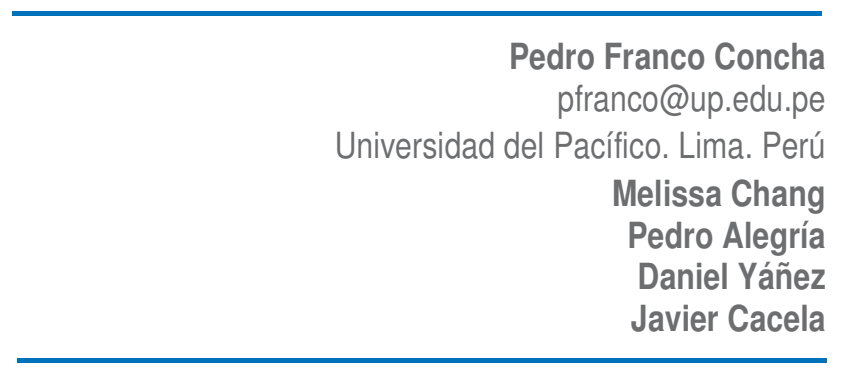

\section{Resumen}

El presente artículo se fundamenta en un cambio sustancial en el tratamiento tributario de las diferencias de cambio de pasivos asociados a la compra de inventarios y activo fijo. Tiene como objetivo determinar si estos cambios tienen un impacto significativo en la interpretación de los principales indicadores financieros de las empresas que operan en el Perú y cuya contabilidad se basa en los lineamientos de la normativa tributaria.

Para poder determinar si existe realmente dicho impacto, se analizaron tanto las normas contables como tributarias y se desarrolló un modelo de evaluación financiera, que permitió examinar las variaciones de los ratios seleccionados para la investigación en respuesta al cambio de la normativa y según distintos escenarios propuestos.

A partir de los resultados obtenidos del modelo descrito previamente, se llegó a la conclusión de que existe una ligera a mediana tendencia a la distorsión de los principales indicadores financieros, producida por la modificación en el tratamiento tributario de la diferencia en cambio.

Finalmente, es recomendable realizar un análisis minucioso al momento de evaluar entidades cuya contabilidad está basada en la normativa tributaria, puesto que con el más reciente tratamiento de la diferencia en cambio, la situación financiera de la empresa podría interpretarse erróneamente si se interpretan únicamente los ratios, ya que podría presentar señales de mejora o deterioro cuando en realidad se mantiene constante.

Palabras clave: Tratamiento tributario, indicadores financieros, diferencia de cambio.

Franco-Concha, P., Chang, M., Alegría, P., Yáñez, D. y Cacela, J. (2012). Efectos de la modificación en el tratamiento de la diferencia en cambio: impacto contable y financiero. Journal of Business, Vol.4(1): 2-23. 


\section{Introducción}

Las diferencias entre la normativa contable y la tributaria han sido siempre motivo de discusión entre los especialistas de ambos temas. Uno de los principales asuntos que ha sufrido cambios es el referente al tratamiento tributario de la diferencia en cambio.

Dentro de este tema general, uno de los puntos en los cuales existía una diferencia significativa es el tratamiento tributario de las diferencias de cambio de pasivos en moneda extranjera relacionados a la adquisición de existencias y activo fijo. En este sentido, mientras que la normativa tributaria disponía que estas deban afectar el costo de los activos, la Norma Internacional de Contabilidad 21 Efectos de las variaciones en las tasas de cambio de la moneda extranjera señala que deben imputarse a los resultados del período.

Con la entrada en vigencia del Decreto Legislativo 1112, promulgado por el Poder Ejecutivo en Julio de 2012, dicha divergencia fue eliminada a partir del 01 de Enero de 2013.

Desde este punto de vista, los cambios introducidos podrían tener impacto en los principales indicadores financieros de las empresas que llevan su contabilidad, fundamentalmente, de acuerdo con la normativa tributaria. Esta situación puede llevar a una lectura distorsionada del estado real de las empresas y, por lo tanto, a decisiones financieras erróneas.

Los cambios en la normativa tributaria respecto al tratamiento de las diferencias de cambio de pasivos asociados a la compra de inventarios y activo fijo han contribuido con el proceso de armonización con el marco contable de las Normas Internacionales de Información Financiera (NIIF). Sin embargo, las organizaciones que basan su contabilidad en las normas fiscales deben adoptar estas modificaciones, con lo cual sus indicadores financieros podrían sufrir variaciones favorables o desfavorables, a pesar de que la situación de estas empresas se mantenga constante.

El presente artículo se contextualizará en el periodo previo a la entrada en vigencia del D.L. 1112 y se enfocará en las empresas que operan en el Perú y cuya contabilidad tiene su fundamento en los lineamientos establecidos en la normativa tributaria peruana.

En la misma línea, el análisis financiero se centrará en las variaciones producidas en los principales indicadores financieros relacionados con el tema. Como hipótesis de partida se plantea, que la modificación en el tratamiento tributario de la diferencia en cambio conlleva a tener perspectivas distorsionadas de la situación financiera de la empresa. A partir de ello se plantea el objetivo de determinar si existe distorsión en la percepción de la situación financiera de una empresa debido a la modificación en el tratamiento tributario de la diferencia en cambio. Para lo cual será preciso: definir las diferencias entre el tratamiento tributario de la diferencia cambio y la práctica contable; proponer un modelo de evaluación financiera y análisis sensibilidad; y cuantificar el impacto de los cambios en los principales indicadores financieros. 


\section{Marco conceptual}

Para propósitos de la presente investigación, es necesario obtener primero un entendimiento del marco contable y tributario tanto previo como posterior a la emisión del Decreto Legislativo 1112. A continuación se presentará la información relevante.

\section{-Antecedentes}

En Junio del 2012, mediante la Ley № 29884, el Congreso de la República delega al Poder Ejecutivo la facultad de legislar en materia tributaria y aduanera por un plazo de cuarenta y cinco días. Dentro de dichas facultades, se autoriza la modificar la Ley del Impuesto a la Renta debido a las siguientes razones:

- Costos para los contribuyentes y la Administración Tributaria generados por una serie de deficiencias y vacíos legales detectadas.

- Desigual afectación en supuestos similares en perjuicio del contribuyente.

- Elevados niveles de evasión del impuesto por la complejidad de las normas vigentes del impuesto.

El mencionado dispositivo legal establece que el objetivo es el de modificar algunas normas del Impuesto a la Renta para dotarlo de mayor neutralidad y equidad, reducir los mecanismos elusivos, establecer un mayor control, así como contar con mayor claridad en su aplicación, reduciendo costos y simplificando su aplicación; y, en general, que permitan que se eleven los niveles de recaudación. Asimismo, la promulgación de dicha norma se contextualiza en la evolución positiva de la presión tributaria, la cual se ha incrementado desde 2010 luego de una caída por la crisis financiera internacional del 2009, como se puede observar en el gráfico 1.

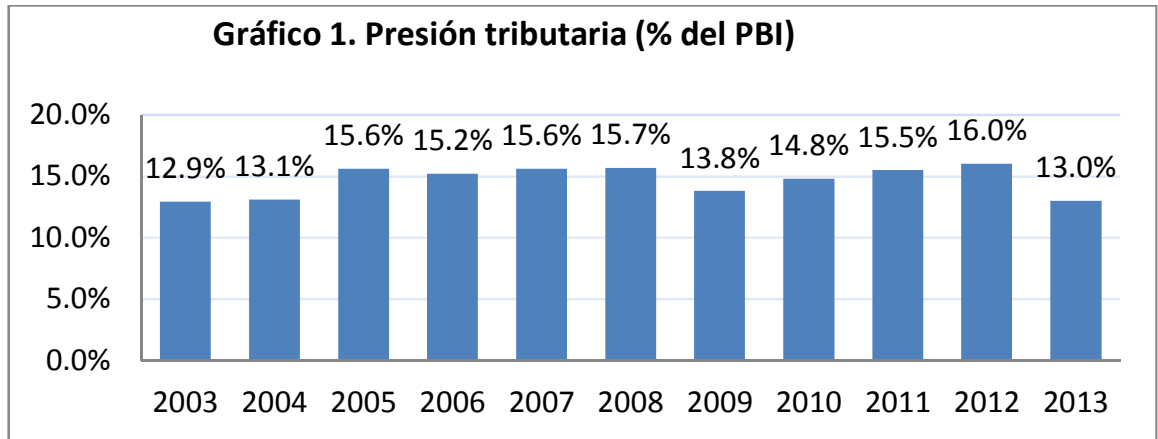

Fuente: SUNAT

-Marco previo a la entrada en vigencia del Decreto Legislativo 1112 (2012): el marco contable y el marco tributario.

\section{-Marco Contable}

El artículo 223 de la Ley General de Sociedades (Ley 26887) establece que "los estados financieros se preparan y presentan de conformidad con las disposiciones legales sobre la materia y con principios de contabilidad generalmente aceptados en el país." Posteriormente, el Consejo Normativo de Contabilidad (CNC) mediante la Resolución № 013-98-EF/93.01, define que los principios de contabilidad generalmente aceptados 
en el Perú incluyen las Normas Internacionales de Contabilidad oficializadas por el CNC y las normas de entidades de control para las áreas que correspondan, siempre y cuando se adecuen al marco teórico de las NIC.

Desde el año 1996, el CNC ha oficializado diversas normas internacionales a medida que estas son emitidas por el Consejo de Normas Internacionales de Contabilidad (IASB). Al cierre de 2012, el CNC oficializó la versión 2012 de las Normas Internacionales de Información Financiera (NIIF) mediante la Resolución № 051-2012EF/30, publicada el 14 de noviembre de este año. Esta incluye todas las NIC desde la 1 hasta la 41, así como las NIIF de la 1 a la 13.

Por su parte, respecto a la aplicación de las NIIF en el Perú, la Superintendencia del Mercado de Valores (antes CONASEV) dispuso mediante la Resolución № 102-2010EF.01.1 que las entidades bajo su supervisión deben presentar sus estados financieros bajo NIIF para el ejercicio 2011 o 2012 según el cronograma expuesto. Asimismo, el Artículo 5 de la Ley № 29720 (Ley que Promueve las Emisiones de Valores Mobiliarios y Fortalece el Mercado de Capitales) dispone que las entidades que no se encuentran bajo la supervisión de la SMV, cuyos ingresos anuales por venta de bienes o prestación de servicios o sus activos totales sean iguales o mayores a 3,000 unidades impositivas tributarias (UIT), deben presentar a la SMV sus estados financieros auditados de acuerdo con las NIIF.

Adicionalmente, la Resolución de la Superintendencia del Mercado de Valores (SMV) N 011-2012-SMV/01 define las normas para la presentación de dicha información. En esta se señala que las entidades cuyos ingresos anuales por venta de bienes o prestación de servicios o activos totales sean iguales o mayores a 30,000 UIT al cierre del ejercicio 2012, deben presentar a la SMV sus estados financieros auditados al 31 de diciembre de 2012. No obstante, se exige que estas entidades apliquen las NIIF a partir del ejercicio 2013.

Para propósitos de la presente investigación, es importante destacar las NIC que pueden influir en el tratamiento contable de las diferencias de cambio. Al respecto, La NIC 21 Efectos de las variaciones en las tasas de cambio de la moneda extranjera establece parámetros para la contabilización de saldos y transacciones en moneda extranjera, así como para la conversión de estados financieros a una moneda distinta.

Inicialmente, dicha norma señala que las transacciones en moneda extranjera deben registrarse a través de la aplicación del tipo de cambio de contado a la fecha de la transacción al monto en moneda extranjera.

Asimismo, las diferencias de cambio que se originen a partir de la liquidación de partidas monetarias o de la conversión de estas a tipos de cambio distintos a los utilizados inicialmente, deben reconocerse en los resultados del período, excepto en casos específicos de partidas relacionadas a inversiones netas en un negocio extranjero.

Al final de cada ejercicio, las partidas monetarias en moneda extranjera deben convertirse al tipo de cambio de cierre de esa fecha. Por otro lado, las partidas no monetarias en moneda extranjera que se midan al costo histórico deben convertirse usando el tipo de cambio de la fecha de la transacción. Las partidas no monetarias en 
moneda extranjera que se midan al valor razonable deben convertirse usando el tipo de cambio de la fecha en que se defina el valor razonable.

Finalmente, la NIC 21 establece que los efectos impositivos que se pudieran generar a partir de ganancias y pérdidas por diferencia en cambio se deben contabilizar a través de la aplicación de la NIC 12 Impuesto a las ganancias. A su vez, esta norma señala que deben reconocerse activos o pasivos de naturaleza fiscal cuando existan diferencias temporales entre el valor en libros de un activo o pasivo y su base fiscal.

\section{-Marco Tributario}

El Texto Único Ordenado de la Ley del Impuesto a la Renta señala en su Artículo 61, que para efectos de la determinación del impuesto por operaciones en moneda extranjera, se aplicarán las siguientes normas:

a) Las operaciones en moneda extranjera se contabilizarán al tipo de cambio vigente a la fecha de la operación.

b) Las diferencias de cambio que resulten del canje de la moneda extranjera por moneda nacional, se considerarán como ganancia o como pérdida del ejercicio en que se efectúa el canje.

c) Las diferencias de cambio que resulten de los pagos o cobranzas por operaciones pactadas en moneda extranjera, contabilizadas en moneda nacional, que se produzcan durante el ejercicio se considerarán como ganancia o como pérdida de dicho ejercicio.

d) Las diferencias de cambio que resulten de expresar en moneda nacional los saldos de moneda extranjera correspondientes a activos y pasivos, deberán ser incluidas en la determinación de la materia imponible del período en el cual la tasa de cambio fluctúa, considerándose como utilidad o como pérdida.

e) Las diferencias de cambio originadas por pasivos en moneda extranjera relacionados y plenamente identificables, ya sea que se encuentren en existencia o en tránsito a la fecha del balance general, deberán afectar el valor neto de los inventarios correspondientes. Cuando no sea posible identificar los inventarios con el pasivo en moneda extranjera, la diferencia de cambio deberá afectar los resultados del ejercicio.

f) Las diferencias de cambio originadas por pasivos en moneda extranjera relacionadas con activos fijos existentes $o$ en tránsito $u$ otros activos permanentes a la fecha del balance general, deberán afectar el costo del activo. Esta norma es igualmente de aplicación en los casos en que la diferencia de cambio esté relacionada con los pagos efectuados en el ejercicio. La depreciación de los activos así reajustados por diferencias de cambio, se hará en cuotas proporcionales al número de años que falten para depreciarlos totalmente.

g) Las inversiones permanentes en valores en moneda extranjera se registrarán y mantendrán al tipo de cambio vigente de la fecha de su adquisición, cuando califiquen como partidas no monetarias.

En síntesis, este artículo establece el tratamiento de las diferencias de cambio en las operaciones para efectos de la determinación de la renta imponible. Asimismo, cabe 
resaltar que los incisos e) y f) disponen la capitalización de las diferencias de cambio para los inventarios y activos fijos.

Por otro lado, tanto el Tribunal Fiscal como la Superintendencia Nacional de Aduanas y Administración Tributaria (SUNAT) han emitido jurisprudencia respecto a las diferencias de cambio en el ámbito del impuesto a la renta, como se puede observar en la línea del tiempo (Ver siguiente página).

El Tribunal Fiscal ha aclarado a través de sus resoluciones que las diferencias en cambio no se consideran para efectos del cálculo de pagos a cuenta, tampoco se consideran gastos comunes en el cálculo del porcentaje de gastos de operaciones gravadas, y que las diferencias en cambio relacionadas a la actividad gravable generan un resultado computable para efectos del impuesto a la renta.

Por el lado de la Superintendencia Nacional de Aduanas y Administración Tributaria (SUNAT), se han emitido informes acerca de las diferencias en cambio que se consideran a fin de determinar la base imponible del impuesto a la renta.

A pesar de que ambos tratan variados temas pudiendo adoptar diversas posturas, observamos que tienen un punto en común: la naturaleza de la diferencia en cambio. En la jurisprudencia se refieren a la diferencia en cambio como un resultado, mas no como parte del activo. Existe una contradicción entre la Ley del Impuesto a la Renta y la jurisprudencia de la SUNAT y el Tribunal Fiscal.

Conclusiones - Marco previo a la vigencia del DL 1112:

A partir del análisis del marco contable y tributario previo a la entrada en vigencia del Decreto Legislativo 1112, se puede distinguir una diferencia sustancial entre ambas posturas respecto al reconocimiento de las diferencias de cambio originadas por pasivos en moneda extranjera asociados a inventarios y activo fijo. Contablemente, la NIC 21 señala que en general las diferencias de cambio deben afectar los resultados del período. Tributariamente, en contraste, la Ley del Impuesto a la Renta dispone que para los casos específicos de las diferencias de cambio de pasivos en moneda extranjera asociados a inventarios y activo fijo, estas deben afectar el valor de los activos.

En este sentido, para el caso de activos fijos se genera una diferencia temporal entre el valor contable del activo y su base tributaria por concepto de diferencia en cambio. Esto significa que se deba reconocer un activo o pasivo por impuesto a la renta diferido por la diferencia entre la depreciación calculada contablemente y la utilizada para propósitos tributarios.

Por otro lado, en el año 2012, las empresas peruanas estaban empezando a adoptar las Normas Internacionales de Información Financiera. Para el cierre de este año, solo estaban obligadas a adoptar las IFRS las entidades supervisadas por la Superintendencia del Mercado de Valores.

Finalmente se observa también la inconsistencia de la naturaleza de la diferencia en cambio en el marco tributario, entre la ley del impuesto a la renta y la jurisprudencia por parte de la SUNAT y el tribunal fiscal. 
Línea de Tiempo

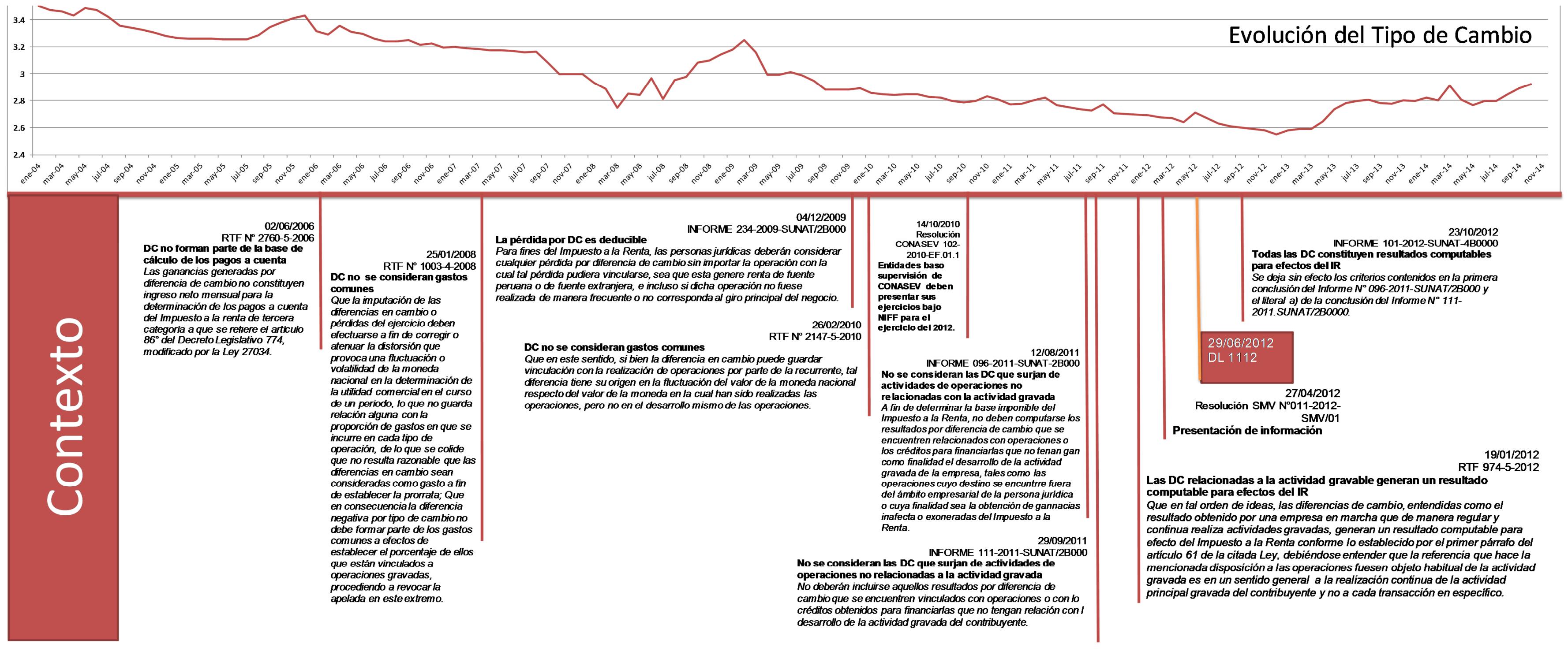


- Marco posterior a la entrada en vigencia del Decreto Legislativo 1112 (2013): marco contable, marco tributario y conclusiones

\section{-Marco contable}

Las Normas Internacionales de Información Financiera siguen adquiriendo importancia como un marco contable de alcance global. Según información del Consejo de Normas Internacionales de Contabilidad (IASB), desde el año 2001 hasta comienzos del 2013, casi 120 países han requerido o permitido el uso de las NIIF. Además, actualmente 15 miembros del G20 (incluyendo la Unión Europea) requieren el uso de las NIIF (IASB, 2013).

Por otro lado, el 01 de enero de 2013 entraron en vigencia diversas normas internacionales. Entre ellas destaca la NIC 27 (Estados financieros separados), NIC 28 (Inversiones en asociadas y negocios conjuntos), NIIF 10 (Estados financieros consolidados), NIIF 11 (Acuerdos conjuntos), NIIF 12 (Información a revelar sobre participaciones en otras entidades) y la NIIF 13 (Medición del valor razonable).

En el Perú, el Consejo Normativo de Contabilidad (CNC) oficializó las NIIF 10, NIIF 12 y NIC 27 mediante la Resolución № 052-2013-EF/30, publicada el 01 de julio de 2013. Además, a través de la Resolución N 052-2013-EF/30, publicada el 11 de setiembre de 2013, el CNC oficializó la versión 2013 de las NIIF, dentro de la cual se incluye las NIC 28, NIIF 11 y NIIF 13.

En cuanto a su aplicación, es importante destacar nuevamente la Resolución de la SMV $N^{\circ}$ 011-2012-SMV/01. En esta se señala que las entidades cuyos ingresos anuales por venta de bienes o prestación de servicios o activos totales sean iguales o mayores a 3,000 UIT al cierre del ejercicio 2013, deben presentar a la SMV sus estados financieros auditados al 31 de diciembre de 2013.

-Marco tributario

El 29 de Junio del 2012, bajo las facultades delegadas por el Congreso de acuerdo con la Ley $N^{\circ} 29884$, el Poder Ejecutivo emite el Decreto Legislativo $N^{\circ} 1112$, cuya vigencia comienza el 01 de enero de 2013. Este decreto modifica la Ley del Impuesto a la Renta respecto a diversos temas, entre los cuales destacan los siguientes:

- El sustento e identificación del costo computable de bienes de distinta naturaleza para efectos de la determinación de la renta bruta.

- Aplicación de una renta presunta de primera categoría e intereses presuntos para transacciones entre vinculadas.

- Definiciones de dividendos y otras formas de distribuciones de utilidades para propósitos del Impuesto a la Renta.

- Determinación del valor de mercado de los valores.

- Normas específicas respecto a los precios de transferencia y transacciones entre vinculadas.

- Excepciones para deducir pérdidas de capital para el impuesto de segunda categoría

- Depreciación de costos posteriores de activos fijos 
- Aplicación de las deducciones por donaciones para determinar la renta neta de tercera categoría y la renta neta de trabajo

- Tasas impositivas a las rentas de capital

- Retenciones a cargo de las instituciones de compensación y liquidación de valores

- Reconocimiento de las diferencias de cambio aplicables a existencias y activo fijo

Para efectos de la presente investigación, es importante profundizar este último concepto. Al respecto, la única disposición complementaria derogatoria deja sin efecto los incisos (e) y (f) del artículo 61 de la Ley del Impuesto a la Renta. Estos señalaban que las diferencias de cambio que surgen por pasivos en moneda extranjera asociados a existencias o activo fijo deben afectar el valor de los mismos.

Además, la quinta disposición complementaria final establece que las diferencias de cambio a las que se refieren los incisos (e) y (f) de la Ley, generadas a partir de la entrada en vigencia del decreto legislativo en cuestión, se regirán por lo señalado en el inciso (d) del artículo 61 de la Ley. Esto significa que las diferencias de cambio originadas por pasivos en moneda extranjera relacionados a existencias o activo fijo deben reconocerse como parte de los resultados del período al que correspondan.

Asimismo, según la tercera disposición complementaria transitoria, las diferencias de cambio a las que se refieren los incisos (e) y (f) de la Ley, generadas hasta antes de la derogación de estos incisos, seguirán rigiéndose por lo señalado en los mismos. Esto implica que hasta el 31 de diciembre de 2012, las diferencias de cambio surgen por pasivos en moneda extranjera asociados a existencias o activo fijo deben afectar el valor de los activos. A partir del 01 de enero de 2013, estas diferencias de cambio deben reconocerse en resultados.

Más aún, resulta relevante destacar los fundamentos sobre los cuales se sustenta este cambio en la normativa tributaria. Al respecto, la exposición de motivos del Decreto Legislativo N¹112 menciona como un problema que los incisos (e) y (f) del Artículo 61 de la Ley del Impuesto a la Renta complican el control de la SUNAT sobre el valor de los inventarios y activos fijos, y de la depreciación para estos últimos. Además, se señala que el contribuyente incurre en sobrecostos injustificados para cumplir con lo establecido por dichos incisos.

Respecto a los inventarios, se argumenta que resulta complicado determinar si un pasivo en moneda extranjera está relacionado o identificado con las existencias, requisito para que la diferencia de cambio se ajuste contra el valor de los inventarios. Asimismo, puede suceder que algunos contribuyentes tengan que manejar un sistema de contabilidad de costos, aun cuando no estén obligados, puesto que esta es la herramienta que permite asignar las diferencias de cambio al valor de los inventarios. Por lo tanto, se genera un sobrecosto y dificultades de control por parte de SUNAT y del mismo contribuyente.

En cuanto a los activos fijos, se menciona que el control también es complejo debido a que se debe comprobar que la diferencia en cambio y su correspondiente depreciación forma parte del valor del activo. Además, la volatilidad del tipo de cambio ocasiona que 
se deban realizar ajustes continuos, con lo cual se complica el control sobre el valor de los activos y la depreciación de las diferencias de cambio.

Asimismo, se expone que según la NIC 21, el criterio general para el reconocimiento de las diferencias de cambio consiste en contabilizarlas en los resultados del ejercicio. Esto refleja una diferencia entre la norma contable y la tributaria previa a la entrada en vigencia del dispositivo legal. En este sentido, se argumenta que se generan contingencias en los casos de diferencias de cambio vinculadas a bienes del activo fijo, puesto que conforme al inciso b) del artículo 22 del reglamento de la LIR, la depreciación aceptada tributariamente será aquella que se encuentre contabilizada dentro del ejercicio gravable en los libros y registros contables, siendo que aun cuando tributariamente tales diferencias de cambio forman parte del costo $\mathrm{y}$, por ende, son depreciables, contablemente las mismas afectan los resultados del ejercicio, por lo que no son contabilizadas como depreciación.

En resumen, se argumenta que el cambio de la norma tributaria eliminaría los sobrecostos y las complicaciones en el control debido al reconocimiento de las diferencias de cambio como parte del costo de los inventarios y activos fijos. De la misma manera, se eliminarían las contingencias que surgen a partir de la diferencia mencionada entre la norma tributaria y la contable.

\section{-Conclusiones - Marco posterior a la vigencia del DL 1112}

El Decreto Legislativo № 1112 establece que, para efectos tributarios, las diferencias de cambio que surgen por pasivos en moneda extranjera asociados a existencias y activo fijo deben formar parte de la renta imponible de cada período. Por lo tanto, luego de la entrada en vigencia de esta norma (01 de enero de 2013), la diferencia clave entre la perspectiva contable y la tributaria sobre este tema deja de existir.

Entonces, a partir del 01 de enero de 2013 se produce una armonización entre el marco de las NIIF y la normativa tributaria peruana en dicho aspecto. En este sentido, esta uniformización ocasiona que no se generen mayores diferencias temporales entre el valor contable y la base tributaria de los activos fijos por diferencias de cambio y a su vez el activo o pasivo por impuesto a la renta diferido asociado.

A partir del marco tributario expuesto, a fin de ilustrar y tener un mayor entendimiento del tratamiento previo y posterior al cambio del artículo 61 de la Ley del impuesto a la renta, se desarrollarán dos casos a modo de ejemplo:

- Tratamiento Previo al DL 1112

A pesar de que la LIR indica que las diferencias de cambio originadas por pasivos en moneda extranjera relacionadas con activos fijos existentes o en tránsito $u$ otros activos permanentes a la fecha del balance general deberán afectar el costo del activo, surgen complicaciones en el ajuste por la diferencia de cambio de la depreciación de los activos.

Esto se debe a que dicha ley en el artículo $61^{\circ}$, inciso f), indica que se depreciará el ajuste por diferencias de cambio en cuotas proporcionales al número de periodos que resten de la vida útil; sin embargo, este supone que la vida útil es mayor a la duración del pasivo, es decir, que aún quedan periodos para depreciar el reajuste respectivo. 
En el caso de que la vida útil del activo sea igual a la duración del pasivo, el último ajuste (producido por el último pago) no tendría periodos en los cuales devengarse a través de la depreciación por lo que formaría parte del resultado del periodo como ingreso o gasto financiero. Tal es el caso de los activos fijos adquiridos bajo la modalidad de arrendamiento financiero que, según el artículo $18^{\circ}$ del D. Leg. 299 y modificado por la Ley 27394 , se deprecian de acuerdo con la duración del contrato respectivo.

Por ello, se consideró importante analizar dos perspectivas: la depreciación retrospectiva y la prospectiva. La diferencia entre ambas es que al registrarse la diferencia de cambio al final de un periodo, el ajuste en la depreciación por este se puede depreciar entre los periodos posteriores a éste que ya ha finalizado según lo interpretado de la norma tributaria (depreciación prospectiva), o entre los periodos posteriores y el periodo finalizado lo que propiciaría el calce en el caso de que la vida útil sea igual a la duración del pasivo (depreciación retrospectiva).

En los siguientes casos se explicarán mejor ambas circunstancias y su desarrollo:

Caso 1 - Vida Útil es mayor a la Vida del Pasivo.

Una empresa adquiere una maquinaria por 10000 USD al TC:3.10 a 2 cuotas mensuales. La vida útil del activo es de 3 meses.

- $\quad$ El TC Vigente en el pago de la 1era cuota es: 3.20

- $\quad$ El TC Vigente en el pago de la 2da cuota es: 3.30

\begin{tabular}{|c|c|c|c|}
\hline Adquisición & Cuota 1 & Cuota 2 & $\begin{array}{c}\text { Término de } \\
\text { Vida Útil }\end{array}$ \\
\hline 31000 & 16000 & 16500 & 0 \\
\hline $\begin{array}{r}\text { Diferencia de } \\
\text { cambio }\end{array}$ & $\begin{array}{c}\text { DC Cuota 1: } 500 \\
\text { DC Saldo: } 500\end{array}$ & DC Cuota 2: 500 & \\
\hline $\begin{array}{l}\text { Depreciación } \\
\text { Prospectiva }\end{array}$ & & Dep 1: 500 & $\begin{array}{l}\text { Dep 1: } 500 \\
\text { Dep 2: } 500\end{array}$ \\
\hline $\begin{array}{l}\text { Depreciación } \\
\text { Retrospectiva }\end{array}$ & Dep 1: 333.3 & $\begin{array}{c}\text { Dep 1: } 333.3 \\
\text { Dep 2: } 250\end{array}$ & $\begin{array}{c}\text { Dep 1: } 333.3 \\
\text { Dep 2: } 250\end{array}$ \\
\hline
\end{tabular}

En este primer caso, observamos que se puede depreciar totalmente el reajuste por la diferencia de cambio al término de la vida útil del activo, tanto prospectiva como retrospectivamente. No surgen mayores complicaciones.

\section{Caso 2 - Vida útil igual a la Vida del Pasivo}

Una empresa adquiere una maquinaria por 10000 USD al TC 3.10 a 2 cuotas mensuales. La vida útil del activo es de 2 meses. 
- $\quad$ El TC Vigente en el pago de la 1era cuota es: 3.20

- $\quad$ El TC Vigente en el pago de la 2da cuota es: 3.30

\begin{tabular}{|c|c|c|c|}
\hline Adquisición & Cuota 1 & Cuota 2 & \\
\hline 31000 & 16000 & 16500 & \\
\hline $\begin{array}{r}\text { Diferencia de } \\
\text { cambio }\end{array}$ & $\begin{array}{l}\text { DC Cuota 1: } 500 \\
\text { DC Saldo: } 500\end{array}$ & DC Cuota 2: 500 & \\
\hline $\begin{array}{c}\text { Depreciación } \\
\text { Prospectiva }\end{array}$ & & Dep 1: 1000 & $\begin{array}{l}\text { Resultado } \\
\text { Financiero: } 500\end{array}$ \\
\hline $\begin{array}{l}\text { Depreciación } \\
\text { Retrospectiva }\end{array}$ & Dep 1: 500 & $\begin{array}{l}\text { Dep 1: } 500 \\
\text { Dep 2: } 500\end{array}$ & \\
\hline
\end{tabular}

Se observa que cuando la vida útil del activo es igual al de la deuda, queda un reajuste por diferencia de cambio sin poderse depreciar ya que se termina la vida útil del activo. El reajuste se tendría que tratar como un resultado financiero, lo cual contradice lo dispuesto en la LIR.

Por casos como este, es posible que haya surgido la perspectiva retrospectiva, en el cual este error es corregido al depreciarlo incluyendo el mismo periodo en el que ocurre la diferencia de cambio, de manera que el reajuste por la diferencia de cambio se logra depreciar totalmente.

\section{- Tratamiento Posterior al DL 1112}

Posteriormente, a través del D.L. 1112, se modifica el tratamiento de las diferencias de cambio originadas a partir de la liquidación de partidas monetarias o de la conversión de estas a tipos de cambio distintos a los utilizados inicialmente. Estos deben reconocerse en los resultados del período. Este cambio simplifica el tratamiento ya que solo se reconocen como resultados financieros.

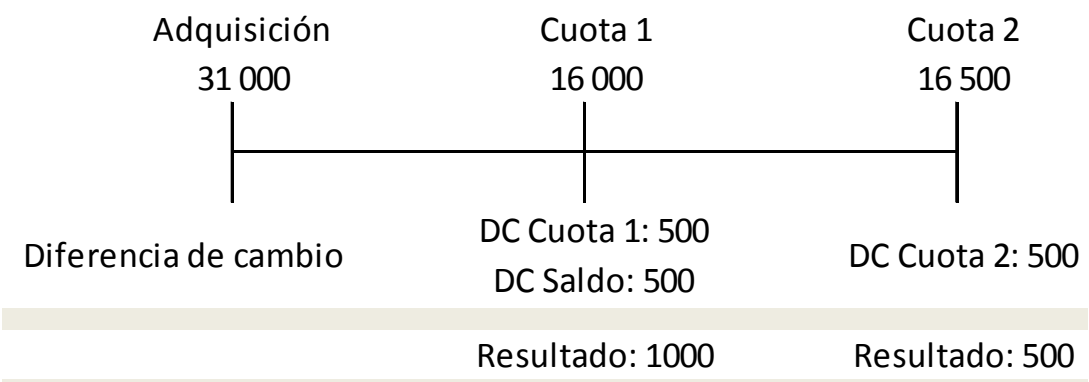


Franco-Concha, P., Chang, M., Alegría, P., Yáñez, D. y Cacela, J. (2012). Efectos de la modificación en el tratamiento de la diferencia en cambio: impacto contable y financiero. Journal of Business, Vol.4(1): 2-23.

\section{Metodología: evaluación financiera}

Las secciones precedentes explicaron con detalle los dos tratamientos de la diferencia en cambio relacionados con activos fijos y existencias. La presente, tiene como propósito determinar si en el cambio en el tratamiento (pasar de capitalización a devengo) existe un impacto significativo en la percepción de la situación financiera de la empresa a través de la interpretación de los principales indicadores o ratios.

Para poder lograr este objetivo, se elaboró un modelo de análisis financiero que además incorpora un análisis de sensibilidad respecto de la variación en el tipo de cambio y otras variables relevantes. Para considerar los dos métodos de aplicación (prospectiva y retroactiva) mencionados en la sección previa, se desarrollaron dos modelos paralelos que difieren únicamente en dicho tema.

\section{-Modelo de evaluación}

Los modelos han sido probados en diferentes escenarios y con diferentes valores para las variables que incorpora. Estas pruebas muestran resultados consistentes y sin errores, lo que los valida como un medio adecuado para cumplir el objetivo planteado.

La información utilizada para elaborarlos parte básicamente del análisis de los Estados Financieros Individuales de los periodos 2011 y 2012 de seis empresas que listan en la Bolsa de Valores de Lima y que fueron tomadas como referentes para la evaluación por el nivel de activos fijos que necesitan para su operación. Éstas son:

- Cementos Pacasmayo S.A.A.

- Unión Andina de Cementos S.A.A.

- Corporación Aceros Arequipa S.A.A.

- Empresa Siderúrgica del Perú S.A.A.

- Unión de Cervecerías Peruanas Backus y Johnston S.A.A.

- Edegel S.A.A.

Es importante señalar también que los bienes de capital que utilizan estas empresas son activos que no se comercializan de manera frecuente en nuestro país y que son principalmente importados por lo que su financiamiento es naturalmente en moneda extranjera.

Para lograr evaluar el impacto del cambio en el tratamiento de la diferencia en cambio, consideramos necesario proyectar estados financieros de acuerdo con supuestos que parten de la información obtenida de las empresas referentes. 
Los datos obtenidos de los informes auditados de cada empresa y relevantes para el trabajo de investigación se presentan en el siguiente cuadro:

\begin{tabular}{|c|c|c|c|c|c|c|c|c|c|c|c|c|c|c|}
\hline \multirow{2}{*}{ INDICADOR } & \multirow{2}{*}{ CóDIGO } & \multicolumn{2}{|c|}{ CPACASC1 } & \multicolumn{2}{|c|}{ UNACEMC1 } & \multicolumn{2}{|c|}{ CORAREC1 } & \multicolumn{2}{|c|}{ SIDERC1 } & \multicolumn{2}{|c|}{ BACKUSI1 } & \multicolumn{2}{|c|}{ EDEGELC1 } & \\
\hline & & 2011 & 2012 & 2011 & 2012 & 2011 & 2012 & 2011 & 2012 & 2011 & 2012 & 2011 & 2012 & \\
\hline ACTIVO FIJO & $1 \mathrm{D} 0205$ & 867,966 & 958,158 & $3,346,367$ & $3,605,739$ & 885,829 & $1,147,068$ & 952,899 & 964,641 & $1,775,563$ & $1,921,858$ & $3,311,869$ & $3,237,108$ & \\
\hline ACTIVO TOTAL & 1D020T & $1,696,688$ & $2,131,134$ & $5,632,719$ & $6,062,625$ & $2,550,643$ & $2,716,787$ & $2,137,873$ & $2,052,857$ & $3,329,269$ & $3,448,182$ & $4,038,545$ & $4,039,526$ & \\
\hline CUENTAS POR COBRAR & 1D0121 & 85,649 & 153,189 & 141,606 & 160,012 & 194,180 & 276,239 & 318,111 & 360,873 & 434,809 & 389,255 & 172,481 & 157,471 & \\
\hline INVENTARIOS & $1 D 0106$ & 167,571 & 238,243 & 353,114 & 419,775 & $1,132,144$ & 900,397 & 700,001 & 628,333 & 194,983 & 180,264 & 65,622 & 68,731 & \\
\hline CUENTAS POR PAGAR & $1 D 0316$ & 92,541 & 92,529 & 283,403 & 241,868 & 281,605 & 311,333 & 109,559 & 79,162 & 676,002 & 837,213 & 133,042 & 246,351 & \\
\hline PAS. FINANCIERO CP & 1D0309 & 125,381 & 22,884 & 537,070 & 873,485 & 595,187 & 669,329 & 463,987 & 381,812 & 110,623 & 115,498 & 107,461 & 117,348 & \\
\hline PAS. FINANCIERO LP & $1 \mathrm{D0401}$ & 424,213 & 192,571 & $1,228,313$ & $1,069,495$ & 322,160 & 347,968 & 416,220 & 573,096 & - & 133,596 & 744,873 & 603,148 & \\
\hline PATRIMONIO TOTAL & 1D07ST & 927,526 & $1,705,801$ & $3,023,549$ & $3,302,563$ & $1,261,377$ & $1,285,302$ & $1,054,966$ & 957,964 & $2,012,460$ & $1,805,056$ & $2,248,043$ & $2,379,254$ & \\
\hline VENTAS & 2D01ST & 656,659 & 784,576 & $1,513,521$ & $1,725,896$ & $2,064,760$ & $2,165,900$ & $1,580,290$ & $1,681,492$ & $3,086,315$ & $3,467,170$ & $1,224,652$ & $1,347,273$ & \\
\hline COSTO DE VENTAS & $2 \mathrm{D0201}$ & $-326,669$ & $-416,507$ & $-851,849$ & $-988,604$ & $-1,609,534$ & $-1,895,949$ & $-1,408,008$ & $-1,716,145$ & $-866,410$ & $-948,173$ & $-757,045$ & $-865,769$ & \\
\hline UTILIDAD OPERATIVA & 2D03ST & 179,818 & 218,549 & 456,743 & 490,280 & 257,083 & 80,819 & 72,705 & $-149,593$ & 961,262 & $1,156,180$ & 434,206 & 452,480 & \\
\hline OTROS INGRESOS OPER & $2 \mathrm{D} 0403$ & 19,526 & 12,099 & 55,753 & 26,269 & 6,980 & 43,612 & 8,595 & 8,537 & 28,597 & 52,944 & 15,008 & 20,082 & \\
\hline OTROS INGRESOS FIN & 2D0401 & 3,474 & 24,850 & 10,212 & 16,956 & 2,447 & 4,367 & 1,138 & 1,114 & 97,509 & 174,972 & 99,026 & 31,941 & \\
\hline UTILIDAD NETA & 2D07ST & 163,063 & 147,703 & 308,381 & 359,794 & 183,874 & 45,881 & 54,749 & $-99,229$ & 730,551 & 948,709 & 285,866 & 307,332 & PROMEDIO \\
\hline ACT. FIJO / ACT. TOTAL & - & $51.16 \%$ & $44.96 \%$ & $59.41 \%$ & $59.47 \%$ & $34.73 \%$ & $42.22 \%$ & $44.57 \%$ & $46.99 \%$ & $53.33 \%$ & $55.74 \%$ & $82.01 \%$ & $80.14 \%$ & $54.56 \%$ \\
\hline DIAS CTAS. POR COBRAR & - & 46.96 & 70.29 & 33.68 & 33.38 & 33.86 & 45.91 & 72.47 & 77.26 & 50.72 & 40.42 & 50.70 & 42.08 & 49.81 \\
\hline DIAS INVENTARIO & - & 184.67 & 205.92 & 149.23 & 152.86 & 253.22 & 170.97 & 178.98 & 131.81 & 81.02 & 68.44 & 31.21 & 28.58 & 136.41 \\
\hline DIAS CTAS. POR PAGAR & - & 101.98 & 79.98 & 119.77 & 88.08 & 62.99 & 59.12 & 28.01 & 16.61 & 280.88 & 317.87 & 63.27 & 102.44 & 110.08 \\
\hline CRECIMIENTO VENTAS & - & & $19.5 \%$ & & $14.0 \%$ & & $4.9 \%$ & & $6.4 \%$ & & $12.3 \%$ & & $10.0 \%$ & $11.19 \%$ \\
\hline MARGEN BRUTO & - & $50 \%$ & $53 \%$ & $56 \%$ & $57 \%$ & $78 \%$ & $88 \%$ & $89 \%$ & $102 \%$ & $28 \%$ & $27 \%$ & $62 \%$ & $64 \%$ & $62.88 \%$ \\
\hline MARGEN OPERATIVO & - & $27.38 \%$ & $27.86 \%$ & $30.18 \%$ & $28.41 \%$ & $12.45 \%$ & $3.73 \%$ & $4.60 \%$ & $-8.90 \%$ & $31.15 \%$ & $33.35 \%$ & $35.46 \%$ & $33.58 \%$ & $21.60 \%$ \\
\hline APALANCAMIENTO & - & $59.25 \%$ & $12.63 \%$ & $58.39 \%$ & $58.83 \%$ & $72.73 \%$ & $79.15 \%$ & $83.43 \%$ & $99.68 \%$ & $5.50 \%$ & $13.80 \%$ & $37.91 \%$ & $30.28 \%$ & $50.97 \%$ \\
\hline
\end{tabular}

Fuente: Bolsa de Valores de Lima 
Uno de los principales supuestos fue utilizar la información financiera de una empresa con un alto nivel de activo fijo. Para determinar lo que representa un alto nivel, obtuvimos el promedio de las empresas referentes (54.56\%) y determinamos que un nivel adecuado para el modelo sería de $50 \%$. Con el objetivo de lograr una mayor eficiencia en el análisis, se estableció el supuesto de que toda la inversión en activo fijo (inicial y posterior) fuera financiada con deuda en moneda extranjera. Esta elección se debe a que es la manera más efectiva de evaluar el contraste e impacto entre los tratamientos de la diferencia en cambio. Sin embargo, el modelo puede ser modificado para asumir distintas formas de financiamiento (y proporción) de las inversiones en activo fijo sin alterar la consistencia del mismo.

Asimismo, se analizaron los niveles de apalancamiento para establecer el ratio de endeudamiento inicial para la evaluación. El resultado obtenido fue que el nivel de apalancamiento promedio de las empresas referentes asciende a 50.97\%. Para efectos prácticos de la proyección, se asumió una estructura inicial de 600,000 nuevos soles de deuda (financiando únicamente activo fijo en su equivalente en dólares) y 600,000 nuevos soles de recursos propios (principalmente contenidos en efectivo), lo cual determina un ratio deuda-patrimonio (a valor en libros) de $50 \%$.

Todos los valores son variables y fueron probados para determinar la consistencia del modelo, a continuación se presentan el resto de supuestos utilizados en el escenario base:

\begin{tabular}{|lr|}
\hline Supuesto & Valor \\
\hline Ingresos primer año & $1,774,875$ \\
\hline Crecimiento ingresos & $11.19 \%$ \\
\hline Margen bruto & $37.12 \%$ \\
\hline Margen EBITDA & $21.60 \%$ \\
\hline Cuentas por cobrar (días de venta) & 49.81 \\
\hline Inventarios (días de costo de venta) & 136.41 \\
\hline Cuentas por pagar (días de costo de venta) & 110.08 \\
\hline Inv. en activo fijo (como \% de ingresos) & $10.00 \%$ \\
\hline Tasa de depreciación & $20.00 \%$ \\
\hline Tasa de interés & $4.00 \%$ \\
\hline Duración de la deuda inicial (años) & 10.00 \\
\hline Duración de la deuda nueva (años) & 5.00 \\
\hline Tasa de impuesto a la renta & $30.0 \%$ \\
\hline Crecimiento terminal & $1.00 \%$ \\
\hline
\end{tabular}

\section{- Variables de entrada}

El método de análisis de sensibilidad exige que se seleccionen variables de entradas o inputs para evaluar la respuesta de variables de salida u outputs ante las variaciones de las primeras ceteris paribus (mientras todo lo demás permanece constante). Con el objetivo de evitar desviarnos del tema de la investigación, se decidió elegir variables que tienen una relación directa con el mismo. Las mismas variables fueron utilizadas en ambos modelos de evaluación, éstas son: 
- Variación de la tasa de tipo de cambio: Se incorporó esta variable para poder evaluar el efecto del cambio en el tratamiento tanto en épocas de apreciación y de depreciación de la moneda nacional frente a la moneda extranjera. Los valores utilizados para el análisis van de $-10 \%$ a $10 \%$ con intervalos de $5 \%$.

- Inversión en activo fijo financiado con deuda: Es indudable que el efecto que tendrá el tratamiento estará relacionado con la forma cómo se financian las compras de activos fijos y existencias. En este caso se decidió utilizar porcentajes que van de $0 \%$ a $100 \%$ con intervalos de $25 \%$.

- Tratamiento de la diferencia en cambio: Es la variable transversal a todos los análisis de indicadores financieros. En este caso se presentan sólo dos valores, "Activo" cuando la diferencia en cambio de los préstamos se computan al costo de los activos fijos y se deprecian de acuerdo con las metodologías y "Resultado" cuando la diferencia en cambio se envía al Estado de Resultados en el periodo en que se producen.

-Variables de salida

Para poder medir el impacto que pueden tener los tratamientos de la diferencia en cambio en cada uno de los escenarios planteados en la investigación, se decidió analizar los ratios e indicadores financieros que tienen mayor relación con el tema. Estos son:

- Solvencia: Calculado como la razón entre el Patrimonio y el Pasivo Total. Este ratio nos indica la capacidad que tiene la empresa para asumir sus obligaciones de mediano y largo plazo.

- Endeudamiento: Calculado como la razón entre Pasivo Total y Activo Total. Muestra la manera el nivel de apalancamiento que tiene la empresa en términos relativos a los activos que posee.

- Cobertura de deuda: Calculado como la división del Pasivo Total entre la Utilidad Operativa Después de Impuestos. Indica cuan solvente puede ser la empresa si tuviera que liquidar sus obligaciones con la utilidad proveniente de la operación.

- Retorno sobre activos: Ratio calculado dividiendo la Utilidad Operativa Después de Impuestos entre el Activo Total Promedio. Muestra el nivel de rentabilidad respecto a los activos que obtiene la empresa en un periodo determinado.

- Retorno sobre patrimonio: Ratio calculado dividiendo la Utilidad Neta entre el Patrimonio Neto Inicial. Muestra el nivel de rentabilidad respecto a los recursos propios que obtiene la empresa en un periodo determinado.

- Valor del patrimonio: Valor descontado de los flujos de caja de la empresa neto de deuda de largo plazo. Permite analizar la generación (o destrucción) de valor considerando el costo del capital. El método utilizado fue el descuento del Flujo de Caja Libre utilizando como tasa el Costo de Capital Medio Ponderado.

- Impuesto a la renta: Determina el pago que debe hacer la empresa por concepto de renta afecta al impuesto respectivo. Este valor depende directamente del margen entre los ingresos, costos y gastos de la empresa en un ejercicio. 


\section{Resultados}

-Solvencia

Se observa que existen diferencias entre la aplicación prospectiva y retroactiva cuando se aplica el tratamiento de capitalización de la diferencia en cambio. Esto se debe a que los gastos por depreciación se devengan en distintos periodos y generan distintos escudos tributarios. Sin embargo, la diferencia entre una aplicación y otra no resulta material.

Este ratio es sensible al tratamiento de las diferencias de cambio. La variación del mismo es inversamente proporcional a la variación del tipo de cambio en el proceso de cambio de tratamiento de la diferencia en cambio. Esto ocurre debido a que en el enfoque de resultados se produce un mayor impacto en la utilidad neta, puesto que se asigna la diferencia de cambio dentro de un solo ejercicio, mientras que bajo el enfoque de activación, esta se distribuye a lo largo de los periodos de vida útil remanentes del activo fijo.

La variación del ratio en el cambio de un tratamiento a otro muestra que efectivamente hay un impacto significativo en la percepción de la solvencia de la empresa si es que se interpreta de manera individual este indicador. Ante periodos de apreciación del tipo de cambio se puede percibir erróneamente que la situación financiera de la empresa empeora y viceversa, sobre todo si consideramos que la volatilidad del tipo de cambio puede ser mayor que el intervalo utilizado para el análisis y si se agrega la forma cómo las empresas financian sus adquisiciones de activo fijo.

\begin{tabular}{|c|c|c|c|c|c|c|c|c|c|c|c|c|c|}
\hline \multirow{2}{*}{$\begin{array}{l}\text { Variación } \\
\text { tipo de } \\
\text { cambio }\end{array}$} & \multicolumn{3}{|c|}{ Aplicación prospectiva } & \multicolumn{3}{|c|}{ Aplicación retroactiva } & \multirow{2}{*}{$\begin{array}{c}\text { CAPEX } \\
\text { financiado } \\
\text { con deuda }\end{array}$} & \multicolumn{3}{|c|}{ Aplicación prospectiva } & \multicolumn{3}{|c|}{ Aplicación retroactiva } \\
\hline & $\begin{array}{c}\text { (a) } \\
\text { Activo }\end{array}$ & $\begin{array}{c}\text { (b) } \\
\text { Resultado }\end{array}$ & $\begin{array}{l}\text { Var. } \\
\text { (b)/(a) }\end{array}$ & $\begin{array}{c}\text { (a) } \\
\text { Activo }\end{array}$ & $\begin{array}{c}\text { (b) } \\
\text { Resultado }\end{array}$ & $\begin{array}{l}\text { Var. } \\
\text { (b)/(a) }\end{array}$ & & $\begin{array}{c}\text { (a) } \\
\text { Activo }\end{array}$ & $\begin{array}{c}\text { (b) } \\
\text { Resultado }\end{array}$ & $\begin{array}{l}\text { Var. } \\
\text { (b)/(a) }\end{array}$ & $\begin{array}{c}\text { (a) } \\
\text { Activo }\end{array}$ & $\begin{array}{c}\text { (b) } \\
\text { Resultado }\end{array}$ & $\begin{array}{l}\text { Var. } \\
\text { (b)/(a) }\end{array}$ \\
\hline $10.0 \%$ & 0.833 & 0.758 & $-9.06 \%$ & 0.804 & 0.758 & $-5.77 \%$ & $100.0 \%$ & 1.108 & 1.100 & $-0.67 \%$ & 1.105 & 1.100 & $-0.43 \%$ \\
\hline $5.0 \%$ & 0.989 & 0.951 & $-3.80 \%$ & 0.975 & 0.951 & $-2.43 \%$ & $75.0 \%$ & 1.293 & 1.286 & $-0.55 \%$ & 1.290 & 1.286 & $-0.34 \%$ \\
\hline $0.0 \%$ & 1.137 & 1.137 & $0.00 \%$ & 1.137 & 1.137 & $0.00 \%$ & $50.0 \%$ & 1.546 & 1.539 & $-0.42 \%$ & 1.543 & 1.539 & $-0.25 \%$ \\
\hline$-5.0 \%$ & 1.278 & 1.314 & $2.89 \%$ & 1.290 & 1.314 & $1.90 \%$ & $25.0 \%$ & 1.916 & 1.910 & $-0.30 \%$ & 1.913 & 1.910 & $-0.15 \%$ \\
\hline$-10.0 \%$ & 1.412 & 1.485 & $5.17 \%$ & 1.435 & 1.485 & $3.45 \%$ & $0.0 \%$ & 2.511 & 2.507 & $-0.17 \%$ & 2.508 & 2.507 & $-0.06 \%$ \\
\hline
\end{tabular}

\section{-Endeudamiento}

Al igual que en el caso anterior, no se observaron diferencias materiales entre la aplicación prospectiva y retroactiva. Respecto a la variación del tipo de cambio, el análisis arrojó resultados poco materiales y con relación directamente proporcional a la variable en mención. El impacto se produce principalmente en el activo (denominador del ratio) por lo que el cambio en el tratamiento hace que en periodos de apreciación del tipo de cambio el nivel de endeudamiento de la empresa aparente ser mayor y lo contrario en periodos de depreciación del tipo de cambio.

A pesar de lo establecido en el párrafo anterior, el efecto no es significativo en términos porcentuales considerando el intervalo del análisis. De igual manera observamos que esta conclusión se repite cuando la variable de análisis es el nivel de financiamiento de la inversión de activo fijo. Sin embargo, debe considerarse que en periodos en los que 
la moneda tenga una apreciación o devaluación de grandes magnitudes, el efecto en este indicador podría volverse relevante.

\begin{tabular}{|c|c|c|c|c|c|c|c|c|c|c|c|c|c|}
\hline \multirow{2}{*}{$\begin{array}{c}\text { Variación } \\
\text { tipo de } \\
\text { cambio }\end{array}$} & \multicolumn{3}{|c|}{ Aplicación prospectiva } & \multicolumn{3}{|c|}{ Aplicación retroactiva } & \multirow{2}{*}{$\begin{array}{c}\text { CAPEX } \\
\text { financiado } \\
\text { con deuda }\end{array}$} & \multicolumn{3}{|c|}{ Aplicación prospectiva } & \multicolumn{3}{|c|}{ Aplicación retroactiva } \\
\hline & $\begin{array}{c}\text { (a) } \\
\text { Activo }\end{array}$ & $\begin{array}{c}\text { (b) } \\
\text { Resultado }\end{array}$ & $\begin{array}{l}\text { Var. } \\
\text { (b)/(a) }\end{array}$ & $\begin{array}{c}\text { (a) } \\
\text { Activo }\end{array}$ & $\begin{array}{c}\text { (b) } \\
\text { Resultado }\end{array}$ & $\begin{array}{l}\text { Var. } \\
\text { (b)/(a) }\end{array}$ & & $\begin{array}{c}\text { (a) } \\
\text { Activo }\end{array}$ & $\begin{array}{c}\text { (b) } \\
\text { Resultado }\end{array}$ & $\begin{array}{l}\text { Var. } \\
\text { (b)/(a) }\end{array}$ & $\begin{array}{c}\text { (a) } \\
\text { Activo }\end{array}$ & $\begin{array}{c}\text { (b) } \\
\text { Resultado }\end{array}$ & $\begin{array}{l}\text { Var. } \\
\text { (b)/(a) }\end{array}$ \\
\hline $10.0 \%$ & 0.554 & 0.578 & $4.41 \%$ & 0.563 & 0.578 & $2.74 \%$ & $100.0 \%$ & 0.486 & 0.488 & $0.38 \%$ & 0.487 & 0.488 & $0.25 \%$ \\
\hline $5.0 \%$ & 0.513 & 0.524 & $2.01 \%$ & 0.517 & 0.524 & $1.28 \%$ & $75.0 \%$ & 0.451 & 0.453 & $0.34 \%$ & 0.452 & 0.453 & $0.22 \%$ \\
\hline $0.0 \%$ & 0.480 & 0.480 & $0.00 \%$ & 0.480 & 0.480 & $0.00 \%$ & $50.0 \%$ & 0.412 & 0.413 & $0.30 \%$ & 0.412 & 0.413 & $0.18 \%$ \\
\hline$-5.0 \%$ & 0.452 & 0.445 & $-1.71 \%$ & 0.450 & 0.445 & $-1.15 \%$ & $25.0 \%$ & 0.368 & 0.369 & $0.25 \%$ & 0.368 & 0.369 & $0.15 \%$ \\
\hline$-10.0 \%$ & 0.429 & 0.415 & $-3.19 \%$ & 0.424 & 0.415 & $-2.20 \%$ & $0.0 \%$ & 0.318 & 0.319 & $0.21 \%$ & 0.318 & 0.319 & $0.11 \%$ \\
\hline
\end{tabular}

\section{-Cobertura de deuda}

En este caso particular, el ratio de cobertura de deuda constituye la única de las variables de salida planteadas previamente que no se afecta debido a la modificación en el tratamiento de las diferencias de cambio ni a la aplicación de los métodos.

Considerando que este ratio mide la capacidad que las empresas poseen para cubrir su deuda con resultados operativos, no es de extrañar que no se vean impactados por el cambio de tratamiento.

Las diferencias en cambio se cargan o abonan a los pasivos y no se ve afectada la utilidad operativa. Claramente este ratio se ve afectado por el aumento o disminución del valor en libros de la deuda al momento del cálculo, pero este motivo no guarda relación con el tema de la investigación.

\begin{tabular}{|c|c|c|c|c|c|c|c|c|c|c|c|c|c|}
\hline \multirow{2}{*}{$\begin{array}{c}\text { Variación } \\
\text { tipo de } \\
\text { cambio }\end{array}$} & \multicolumn{3}{|c|}{ Aplicación prospectiva } & \multicolumn{3}{|c|}{ Aplicación retroactiva } & \multirow{2}{*}{$\begin{array}{c}\text { CAPEX } \\
\text { financiado } \\
\text { con deuda }\end{array}$} & \multicolumn{3}{|c|}{ Aplicación prospectiva } & \multicolumn{3}{|c|}{ Aplicación retroactiva } \\
\hline & $\begin{array}{c}\text { (a) } \\
\text { Activo }\end{array}$ & $\begin{array}{c}\text { (b) } \\
\text { Resultado }\end{array}$ & $\begin{array}{l}\text { Var. } \\
\text { (b)/(a) }\end{array}$ & $\begin{array}{c}\text { (a) } \\
\text { Activo }\end{array}$ & $\begin{array}{c}\text { (b) } \\
\text { Resultado }\end{array}$ & $\begin{array}{l}\text { Var. } \\
\text { (b)/(a) }\end{array}$ & & $\begin{array}{c}\text { (a) } \\
\text { Activo }\end{array}$ & $\begin{array}{c}\text { (b) } \\
\text { Resultado }\end{array}$ & $\begin{array}{l}\text { Var. } \\
\text { (b)/(a) }\end{array}$ & $\begin{array}{c}\text { (a) } \\
\text { Activo }\end{array}$ & $\begin{array}{c}\text { (b) } \\
\text { Resultado }\end{array}$ & $\begin{array}{l}\text { Var. } \\
\text { (b)/(a) }\end{array}$ \\
\hline $10.0 \%$ & 2.682 & 2.682 & $0.00 \%$ & 2.682 & 2.682 & $0.00 \%$ & $100.0 \%$ & 2.412 & 2.412 & $0.00 \%$ & 2.412 & 2.412 & $0.00 \%$ \\
\hline $5.0 \%$ & 2.524 & 2.524 & $0.00 \%$ & 2.524 & 2.524 & $0.00 \%$ & $75.0 \%$ & 2.119 & 2.119 & $0.00 \%$ & 2.119 & 2.119 & $0.00 \%$ \\
\hline $0.0 \%$ & 2.386 & 2.386 & $0.00 \%$ & 2.386 & 2.386 & $0.00 \%$ & $50.0 \%$ & 1.826 & 1.826 & $0.00 \%$ & 1.826 & 1.826 & $0.00 \%$ \\
\hline$-5.0 \%$ & 2.264 & 2.264 & $0.00 \%$ & 2.264 & 2.264 & $0.00 \%$ & $25.0 \%$ & 1.533 & 1.533 & $0.00 \%$ & 1.533 & 1.533 & $0.00 \%$ \\
\hline$-10.0 \%$ & 2.157 & 2.157 & $0.00 \%$ & 2.157 & 2.157 & $0.00 \%$ & $0.0 \%$ & 1.240 & 1.240 & $0.00 \%$ & 1.240 & 1.240 & $0.00 \%$ \\
\hline
\end{tabular}

\section{-Retorno sobre activos}

En el análisis de este ratio, no se determinaron diferencias relevantes entre la aplicación prospectiva y la aplicación retrospectiva del tratamiento de activación. La diferencia oscila entre $0.05 \%$ y $0.1 \%$ por lo que no se consideró necesario ahondar en el análisis de este tema.

La exposición del retorno sobre activos a la variación del tipo de cambio muestra que existe un impacto bastante significativo en el cambio de tratamiento. Cuando se aplica el enfoque de resultados, el nivel de activos no se ve afectado por la diferencia en cambio relacionada con los préstamos para la compra de activos fijos, por lo mismo, el ratio oscila de función de la variación de la tasa de cambio.

El efecto de la proporción de financiamiento confirma la exposición de este ratio mostrando una de las variaciones más relevantes de todo el análisis (hasta $2 \%$ ). 
Considerando este ratio, se puede considerar erróneamente que la empresa está obteniendo mayor rentabilidad sobre los activos con el cambio de tratamiento de la diferencia en cambio en periodos de apreciación de la tasa y viceversa.

\begin{tabular}{|c|c|c|c|c|c|c|c|c|c|c|c|c|c|}
\hline \multirow[b]{2}{*}{$\begin{array}{l}\text { Variación } \\
\text { tipo de } \\
\text { cambio }\end{array}$} & \multicolumn{3}{|c|}{ Aplicación prospectiva } & \multicolumn{3}{|c|}{ Aplicación retroactiva } & \multirow{2}{*}{$\begin{array}{c}\text { CAPEX } \\
\text { financiado } \\
\text { con deuda }\end{array}$} & \multicolumn{3}{|c|}{ Aplicación prospectiva } & \multicolumn{3}{|c|}{ Aplicación retroactiva } \\
\hline & $\begin{array}{c}\text { (a) } \\
\text { Activo }\end{array}$ & $\begin{array}{c}\text { (b) } \\
\text { Resultado }\end{array}$ & $\begin{array}{l}\text { Var. } \\
\text { (b)/(a) }\end{array}$ & $\begin{array}{c}\text { (a) } \\
\text { Activo }\end{array}$ & $\begin{array}{c}\text { (b) } \\
\text { Resultado }\end{array}$ & $\begin{array}{l}\text { Var. } \\
\text { (b)/(a) }\end{array}$ & & $\begin{array}{c}\text { (a) } \\
\text { Activo }\end{array}$ & $\begin{array}{c}\text { (b) } \\
\text { Resultado }\end{array}$ & $\begin{array}{l}\text { Var. } \\
\text { (b)/(a) }\end{array}$ & $\begin{array}{c}\text { (a) } \\
\text { Activo }\end{array}$ & $\begin{array}{c}\text { (b) } \\
\text { Resultado }\end{array}$ & $\begin{array}{l}\text { Var. } \\
\text { (b)/(a) }\end{array}$ \\
\hline $10.0 \%$ & $8.04 \%$ & $10.07 \%$ & $25.29 \%$ & $7.93 \%$ & $10.07 \%$ & $27.10 \%$ & $100.0 \%$ & $9.24 \%$ & $9.42 \%$ & $1.93 \%$ & $9.23 \%$ & $9.42 \%$ & $2.01 \%$ \\
\hline $5.0 \%$ & $8.73 \%$ & $9.67 \%$ & $10.79 \%$ & $8.68 \%$ & $9.67 \%$ & $11.38 \%$ & $75.0 \%$ & $9.76 \%$ & $9.92 \%$ & $1.63 \%$ & $9.76 \%$ & $9.92 \%$ & $1.69 \%$ \\
\hline $0.0 \%$ & $9.37 \%$ & $9.37 \%$ & $0.00 \%$ & $9.37 \%$ & $9.37 \%$ & $0.00 \%$ & $50.0 \%$ & $10.34 \%$ & $10.48 \%$ & $1.33 \%$ & $10.34 \%$ & $10.48 \%$ & $1.36 \%$ \\
\hline$-5.0 \%$ & $9.95 \%$ & $9.13 \%$ & $-8.27 \%$ & $9.98 \%$ & $9.13 \%$ & $-8.54 \%$ & $25.0 \%$ & $10.99 \%$ & $11.11 \%$ & $1.02 \%$ & $10.99 \%$ & $11.11 \%$ & $1.03 \%$ \\
\hline$-10.0 \%$ & $10.50 \%$ & $8.95 \%$ & $-14.75 \%$ & $10.54 \%$ & $8.95 \%$ & $-15.11 \%$ & $0.0 \%$ & $11.73 \%$ & $11.82 \%$ & $0.71 \%$ & $11.73 \%$ & $11.82 \%$ & $0.70 \%$ \\
\hline
\end{tabular}

\section{-Retorno sobre patrimonio}

Nuevamente se observa que los métodos de aplicación no generan diferencias relevantes en los escenarios de análisis. De igual manera, se determinó que el cambio de tratamiento resultó en variaciones leves en el retorno sobre patrimonio.

Los escenarios analizados tanto en variación de tipo de cambio y nivel de activo fijo financiado con deuda, muestran que el impacto es poco significativo principalmente debido a que el cambio de enfoque obliga a que las diferencias en cambio se envíen a resultados afectando directamente la utilidad neta y, por ende, el patrimonio de las empresas.

Es claro que podría existir una ligera distorsión en el sentido de que este ratio utiliza el valor del patrimonio neto de inicio del periodo, pero ésta se elimina si se considera el cambio a nivel general en los periodos proyectados. En resumen, la interpretación de este ratio no debería verse afectada por el cambio en el tratamiento.

\begin{tabular}{|c|c|c|c|c|c|c|c|c|c|c|c|c|c|}
\hline \multirow{2}{*}{$\begin{array}{c}\text { Variación } \\
\text { tipo de } \\
\text { cambio }\end{array}$} & \multicolumn{3}{|c|}{ Aplicación prospectiva } & \multicolumn{3}{|c|}{ Aplicación retroactiva } & \multirow{2}{*}{$\begin{array}{c}\text { CAPEX } \\
\text { financiado } \\
\text { con deuda }\end{array}$} & \multicolumn{3}{|c|}{ Aplicación prospectiva } & \multicolumn{3}{|c|}{ Aplicación retroactiva } \\
\hline & $\begin{array}{c}\text { (a) } \\
\text { Activo }\end{array}$ & $\begin{array}{c}\text { (b) } \\
\text { Resultado }\end{array}$ & $\begin{array}{l}\text { Var. } \\
\text { (b)/(a) }\end{array}$ & $\begin{array}{c}\text { (a) } \\
\text { Activo }\end{array}$ & $\begin{array}{c}\text { (b) } \\
\text { Resultado }\end{array}$ & $\begin{array}{l}\text { Var. } \\
\text { (b)/(a) }\end{array}$ & & $\begin{array}{c}\text { (a) } \\
\text { Activo }\end{array}$ & $\begin{array}{c}\text { (b) } \\
\text { Resultado }\end{array}$ & $\begin{array}{l}\text { Var. } \\
\text { (b)/(a) }\end{array}$ & $\begin{array}{c}\text { (a) } \\
\text { Activo }\end{array}$ & $\begin{array}{c}\text { (b) } \\
\text { Resultado }\end{array}$ & $\begin{array}{l}\text { Var. } \\
\text { (b)/(a) }\end{array}$ \\
\hline $10.0 \%$ & $16.59 \%$ & $16.62 \%$ & $0.17 \%$ & $16.50 \%$ & $16.62 \%$ & $0.75 \%$ & $100.00 \%$ & $18.63 \%$ & $18.65 \%$ & $0.11 \%$ & $18.63 \%$ & $18.65 \%$ & $0.13 \%$ \\
\hline $5.0 \%$ & $17.84 \%$ & $17.91 \%$ & $0.39 \%$ & $17.81 \%$ & $17.91 \%$ & $0.55 \%$ & $75.00 \%$ & $18.81 \%$ & $18.85 \%$ & $0.17 \%$ & $18.81 \%$ & $18.85 \%$ & $0.17 \%$ \\
\hline $0.0 \%$ & $18.81 \%$ & $18.81 \%$ & $0.00 \%$ & $18.81 \%$ & $18.81 \%$ & $0.00 \%$ & $50.00 \%$ & $19.00 \%$ & $19.04 \%$ & $0.22 \%$ & $19.00 \%$ & $19.04 \%$ & $0.21 \%$ \\
\hline$-5.0 \%$ & $19.57 \%$ & $19.44 \%$ & $-0.70 \%$ & $19.57 \%$ & $19.44 \%$ & $-0.69 \%$ & $25.00 \%$ & $19.18 \%$ & $19.23 \%$ & $0.28 \%$ & $19.18 \%$ & $19.23 \%$ & $0.25 \%$ \\
\hline$-10.0 \%$ & $20.20 \%$ & $19.88 \%$ & $-1.55 \%$ & $20.17 \%$ & $19.88 \%$ & $-1.45 \%$ & $0.00 \%$ & $19.35 \%$ & $19.41 \%$ & $0.33 \%$ & $19.36 \%$ & $19.41 \%$ & $0.29 \%$ \\
\hline
\end{tabular}

\section{-Valor del patrimonio}

Este es otro de los indicadores que demostró mayor impacto en la evaluación de sensibilidad. Antes de comenzar el análisis específico, es importante destacar que el método de aplicación de la norma tributaria no influye sustancialmente en el resultado obtenido.

Una tendencia clara es que en el enfoque de resultados tanto la variación del tipo de cambio como la forma de financiamiento no tiene un efecto directo en el valor del patrimonio. Esto se debe a que se realizó un análisis ceteris paribus y el monto calculado para la inversión en activo fijo (CAPEX) está en base de los ingresos y éstos se expresan en nuevos soles. Esto no quiere decir que no exista un impacto de la diferencia en 
cambio en el valor de la empresa sino que para efectos de esta investigación no se ha considerado relevante ingresar una variable adicional que calcule este impacto.

El principal motivo por el cual existe una diferencia significativa en el cambio del tratamiento de se debe a la depreciación del activo fijo que se ajusta en el flujo de caja por no representar un desembolso de dinero. Adicionalmente, tiene un efecto directo sobre el escudo fiscal que también supone un incremento o disminución en el flujo de caja. Cuando se traslada del enfoque de activación al enfoque de resultados, se pierde este ajuste y queda un valor libre del efecto de la diferencia en cambio tal y como se ha planteado en la investigación. Este nuevo valor es menor que el anterior en periodos de apreciación del tipo de cambio y mayor en periodos de depreciación. La interpretación de este indicador puede verse distorsionada si no se separan los elementos influenciados por el cambio de tratamiento de la diferencia en cambio.

\begin{tabular}{|c|c|c|c|c|c|c|c|c|c|c|c|c|c|}
\hline \multirow{2}{*}{$\begin{array}{c}\text { Variación } \\
\text { tipo de } \\
\text { cambio }\end{array}$} & \multicolumn{3}{|c|}{ Aplicación prospectiva } & \multicolumn{3}{|c|}{ Aplicación retroactiva } & \multirow{2}{*}{$\begin{array}{c}\text { CAPEX } \\
\text { financiado } \\
\text { con deuda }\end{array}$} & \multicolumn{3}{|c|}{ Aplicación prospectiva } & \multicolumn{3}{|c|}{ Aplicación retroactiva } \\
\hline & $\begin{array}{c}\text { (a) } \\
\text { Activo }\end{array}$ & $\begin{array}{c}\text { (b) } \\
\text { Resultado }\end{array}$ & $\begin{array}{l}\text { Var. } \\
\text { (b)/(a) }\end{array}$ & $\begin{array}{c}\text { (a) } \\
\text { Activo }\end{array}$ & $\begin{array}{c}\text { (b) } \\
\text { Resultado }\end{array}$ & $\begin{array}{l}\text { Var. } \\
\text { (b)/(a) }\end{array}$ & & $\begin{array}{c}\text { (a) } \\
\text { Activo }\end{array}$ & $\begin{array}{c}\text { (b) } \\
\text { Resultado }\end{array}$ & $\begin{array}{l}\text { Var. } \\
\text { (b)/(a) }\end{array}$ & $\begin{array}{c}\text { (a) } \\
\text { Activo }\end{array}$ & $\begin{array}{c}\text { (b) } \\
\text { Resultado }\end{array}$ & $\begin{array}{l}\text { Var. } \\
\text { (b)/(a) }\end{array}$ \\
\hline $10.0 \%$ & $4,672,897$ & $4,071,654$ & $-12.87 \%$ & $4,726,783$ & $4,071,654$ & $-13.86 \%$ & $100.0 \%$ & $4,126,155$ & $4,071,654$ & $-1.32 \%$ & $4,130,792$ & $4,071,654$ & $-1.43 \%$ \\
\hline $5.0 \%$ & $4,356,320$ & $4,071,654$ & $-6.53 \%$ & $4,381,092$ & $4,071,654$ & $-7.06 \%$ & $75.0 \%$ & $4,113,882$ & $4,071,654$ & $-1.03 \%$ & $4,117,634$ & $4,071,654$ & $-1.12 \%$ \\
\hline $0.0 \%$ & $4,071,654$ & $4,071,654$ & $0.00 \%$ & $4,071,654$ & $4,071,654$ & $0.00 \%$ & $50.0 \%$ & $4,101,608$ & $4,071,654$ & $-0.73 \%$ & $4,104,476$ & $4,071,654$ & $-0.80 \%$ \\
\hline$-5.0 \%$ & $3,816,414$ & $4,071,654$ & $6.69 \%$ & $3,795,391$ & $4,071,654$ & $7.28 \%$ & $25.0 \%$ & $4,089,334$ & $4,071,654$ & $-0.43 \%$ & $4,091,319$ & $4,071,654$ & $-0.48 \%$ \\
\hline$-10.0 \%$ & $3,588,223$ & $4,071,654$ & $13.47 \%$ & $3,549,393$ & $4,071,654$ & $14.71 \%$ & $0.0 \%$ & $4,077,061$ & $4,071,654$ & $-0.13 \%$ & $4,078,161$ & $4,071,654$ & $-0.16 \%$ \\
\hline
\end{tabular}

\section{-Impuesto a la renta}

Finalmente, el impacto en el impuesto a la renta se genera a partir de dos factores. El primero es la diferencia en la depreciación que surge por la activación de las diferencias de cambio. Luego, el gasto o ingreso por este concepto que afecta los resultados del ejercicio bajo el nuevo enfoque del tratamiento tributario de las diferencias de cambio. Entonces, si el tipo de cambio sube se pagará un menor monto por impuesto a la renta que anteriormente, y lo contrario ocurrirá en los escenarios de apreciación de la moneda nacional.

La interpretación de este ratio es relativa ya que depende de muchos factores, entre los que se incluyen la variación de la tasa de tipo de cambio, el nivel de inversión en activo fijo financiada con deuda, etc. De cualquier manera se puede establecer que el cambio de tratamiento determina que exista una relación inversa entre la variación de la tasa de cambio y el monto de impuesto a la renta de las empresas.

\begin{tabular}{|c|c|c|c|c|c|c|c|c|c|c|c|c|c|}
\hline \multirow{2}{*}{$\begin{array}{l}\text { Variación } \\
\text { tipo de } \\
\text { cambio }\end{array}$} & \multicolumn{3}{|c|}{ Aplicación prospectiva } & \multicolumn{3}{|c|}{ Aplicación retroactiva } & \multirow{2}{*}{$\begin{array}{c}\text { CAPEX } \\
\text { financiado } \\
\text { con deuda }\end{array}$} & \multicolumn{3}{|c|}{ Aplicación prospectiva } & \multicolumn{3}{|c|}{ Aplicación retroactiva } \\
\hline & $\begin{array}{c}\text { (a) } \\
\text { Activo }\end{array}$ & $\begin{array}{c}\text { (b) } \\
\text { Resultado }\end{array}$ & $\begin{array}{l}\text { Var. } \\
\text { (b)/(a) }\end{array}$ & $\begin{array}{c}\text { (a) } \\
\text { Activo }\end{array}$ & $\begin{array}{c}\text { (b) } \\
\text { Resultado }\end{array}$ & $\begin{array}{l}\text { Var. } \\
\text { (b)/(a) }\end{array}$ & & $\begin{array}{c}\text { (a) } \\
\text { Activo }\end{array}$ & $\begin{array}{c}\text { (b) } \\
\text { Resultado }\end{array}$ & $\begin{array}{l}\text { Var. } \\
\text { (b)/(a) }\end{array}$ & $\begin{array}{c}\text { (a) } \\
\text { Activo }\end{array}$ & $\begin{array}{c}\text { (b) } \\
\text { Resultado }\end{array}$ & $\begin{array}{l}\text { Var. } \\
\text { (b)/(a) }\end{array}$ \\
\hline $10.0 \%$ & 110,384 & 103,469 & $-6.26 \%$ & 108,170 & 107,200 & $-0.90 \%$ & $100.0 \%$ & 141,087 & 140,483 & $-0.43 \%$ & 109,449 & 108,971 & $-0.44 \%$ \\
\hline $5.0 \%$ & 128,607 & 125,399 & $-2.49 \%$ & 109,449 & 108,971 & $-0.44 \%$ & $75.0 \%$ & 144,120 & 143,681 & $-0.30 \%$ & 110,677 & 110,342 & $-0.30 \%$ \\
\hline $0.0 \%$ & 143,954 & 143,954 & $0.00 \%$ & 110,677 & 110,677 & $0.00 \%$ & $50.0 \%$ & 147,153 & 146,879 & $-0.19 \%$ & 111,906 & 111,714 & $-0.17 \%$ \\
\hline$-5.0 \%$ & 156,965 & 159,734 & $1.76 \%$ & 111,856 & 112,321 & $0.42 \%$ & $25.0 \%$ & 150,186 & 150,077 & $-0.07 \%$ & 113,134 & 113,085 & $-0.04 \%$ \\
\hline$-10.0 \%$ & 168,064 & 173,218 & $3.07 \%$ & 112,990 & 113,906 & $0.81 \%$ & $0.0 \%$ & 153,218 & 153,275 & $0.04 \%$ & 114,363 & 114,457 & $0.08 \%$ \\
\hline
\end{tabular}




\section{Conclusiones}

El objetivo general de nuestra investigación se planteó alrededor de la hipótesis de una posible distorsión en la interpretación de indicadores financieros a raíz de la modificación en el tratamiento tributario de la diferencia en cambio de pasivos en moneda extranjera relacionados a la compra de activos fijos.

El modelo de evaluación elaborado para comprobar la hipótesis arrojó como resultado la existencia de una ligera a mediana tendencia a la distorsión de los principales indicadores financieros producida por la modificación en el tratamiento de la diferencia en cambio introducido con el Decreto Legislativo 1112 y de aplicación obligatoria a partir del ejercicio 2013.

Los principales impactos se encontraron en el valor del patrimonio calculado a través del flujo de caja descontado con la tasa de costo de capital medio ponderado y en el ratio de retorno sobre activos. En el primer caso, el indicador se ve influenciado de manera directa por la depreciación que se difiere en el enfoque de activación y que luego se devenga en el enfoque de resultados. En el segundo caso, se ve influenciado principalmente por la diferencia en cambio activada que en el segundo enfoque pasa a resultados dejando sin efecto cualquier variación en el ratio.

Se considera necesario elaborar un análisis cuidadoso al momento de evaluar empresas cuya información contable tiene como fundamento la norma tributaria, ya que con el nuevo tratamiento de la diferencia en cambio podría interpretarse que su situación financiera estaría mejorando o deteriorándose cuando en realidad se mantiene constante.

\section{Referencias bibliográficas}

CONASEV. (2010). Resolución N 102-2010-EF/94.01.1. Lima.

Congreso de la República. (2000). Ley № 27394.

Cosio Jara, M. (s.f.). Controversias contables y tributarias cierre contable 2011 Diferencia de Cambio. Lima, Perú.

De la Torre, D. (2013). Transparencia Fiscal Internacional / Diferencia en cambio. Lima, Perú.

(1984). Decreto Legislativo № 299.

(2012). Decreto Legislativo № 1112. Lima.

Del Rosario, R. (2013). Tratamiento de las Diferencias de Cambio y de las Provisiones. Lima, Perú.

(2012). Exposición de Motivos - Decreto Legislativo que modifica la Ley del Impuesto a la Renta. Lima: El Peruano. 
Flores, C. L. (2010). Diferencia de cambio asociada a Activos Fijos y Existencias. Actualidad Empresarial, I.16 - I.19.

IASB. (2012). Norma Internacional de Contabilidad 12.

IASB. (2012). Norma Internacional de Contabilidad 21.

IASB. (2013). Quiénes somos y qué hacemos. Londres: Fundación IFRS.

Normas Legales. (2011). Ley 29720. Lima: El Peruano.

RSM Perú. (Marzo de 2012). Ganancias por diferencia en cambio. Tax e-News.

SMV. (2012). Resolución № 011-2012-SMV/01. Lima.

SUNAT. (2011). INFORME N. ${ }^{\circ 096-2011-S U N A T / 2 B 0000 . ~ L i m a . ~}$

SUNAT. (2012). INFORME N. ${ }^{\circ}$ 101-2012-SUNAT/4B0000. Lima.

SUNAT. (2011). INFORME N.111-2011-SUNAT/2B0000. Lima.

SUNAT. (2009). INFORME Nº03-2008-SUNAT/2B0000. Lima.

Tribunal Fiscal. (2012). Resolución del Tribunal Fiscal Nº0974-5-2012. Lima.

Tribunal Fiscal. (2008). Resolución del Tribunal Fiscal № 01003-4-2008. Lima.

Tribunal Fiscal. (2010). Resolución del Tribunal Fiscal N 02147-5-2010. Lima.

Tribunal Fiscal. (2006). Resolución del Tribunal Fiscal № 02760-5-2006. Lima. 